\title{
FACÇÕES BRASILEIRAS: UMA REVISÃO
}

\author{
Thaíssa Fernanda Kratochwill de Oliveira ${ }^{1}$
}

RESUMO: O objeto das facções brasileiras é complexo e ainda pouco estudado. Com o objetivo de servir de referência a pesquisadores nele interessados, o presente trabalho consiste em uma revisão integrativa das publicações nacionais sobre o tema das facções brasileiras. Foram identificados os períodos de maior publicação, as regiões que mais publicaram e os subtemas discutidos em cada um dos trabalhos selecionados.

Palavras-chave: Facções brasileiras. Organizações criminosas. Tráfico de drogas. Revisão integrativa.

ABSTRACT: The object of Brazilian factions is complex and still poorly studied. Aiming to serve as a reference for interested researchers, this article means a integrative review of publications on the subject of the brazilian factions. The periods of greatest publication were identified, the regions that published the most and the sub-themes discussed in each of the selected articles.

Keywords: Brasilian factions. Criminal organizations. Drug trafficking. Integrative review.

\section{INTRODUÇÃO}

O objeto das facções brasileiras é complexo e ainda pouco estudado. Os poucos estudiosos do tema por vezes apresentam leituras diferentes sobre os fatos e fenômenos relacionados, gerando controvérsias que se formam desde a conceituação do próprio objeto das facções.

$\mathrm{Na}$ presente análise, adota-se o termo facções brasileiras, o que se justifica pela abrangência que esta nomenclatura comporta, o que é fundamental ao considerar a pluralidade dos grupos que compõem o objeto aqui discutido, mas que, por outro lado, perde ao não fazer referência a nenhuma especificidade além da territorial mais ampla, do Brasil. Tal problemática só pode avançar em resolução à medida em que mais estudos

'Mestra em Psicologia pela Universidade Federal Rural do Rio de Janeiro (UFRRJ). E-mail: thaissa.fko@gmail.com. 
sejam realizados sobre este objeto e que, avançando na compreensão sobre ele, se possa chegar a termos que o mencionem de maneira mais satisfatória. Os termos já utilizados por outros autores e pela mídia, como faç̧ões do tráfico e organizações criminosas, ou mesmo em obras acadêmicas, como firmas, coletivos prisionais ou instituições de autorregulação do crime são considerados aqui como equivocados ou insuficientes, como é discutido a seguir.

Facções do tráfico associa obrigatoriamente os grupos faccionais às atividades de tráfico de drogas e de armas. Um olhar histórico votado ao fenômeno nos informa que as facções surgem muito antes da expansão do tráfico de cocaína e que, em um momento inicial o surgimento dos então chamados "coletivos" no interior das prisões, os quais hoje conhecemos como facções nada tinha a ver com atividades de comércio ilegal de substâncias, mas sim, serviam como organizações pela reivindicação de tratamento digno e como forma de sobreviver às violações sofridas por seus membros no interior das prisões. Amorim (2006); Amorim (20II) e Lima (2016) nos informam sobre o surgimento destes coletivos no Rio de Janeiro e Varella (2017) sobre os de São Paulo. Além disto, por todas as transformações que houveram nestes grupos desde então (bem como o surgimento de outros deles), não é possível continuar tratando-os como coletivos prisionais.

Já as organizações criminosas são objeto de uma lei específica, a lei no $12.850 / 2013$ (BRASIL, 2013) que em seu art. $\mathrm{I}^{\mathrm{o}}$, $\S^{\stackrel{ }{ }}$, define como:

\footnotetext{
Organização criminosa a associação de 4 (quatro) ou mais pessoas estruturalmente ordenada e caracterizada pela divisão de tarefas, ainda que informalmente, com objetivo de obter, direta ou indiretamente, vantagem de qualquer natureza, mediante a prática de infrações penais cujas penas máximas sejam superiores a 4 (quatro) anos, ou que sejam de caráter transnacional.
}

O uso deste termo recai no mesmo erro, afinal é inverídico afirmar que a formação dos coletivos no interior das prisões foi baseada no interesse de praticar infrações penais. Pelo contrário, como nos informa Amorim (2011) e Amorim (2006) recorrer aos roubos a banco e outras atividades criminosas estava centrado no financiamento dos coletivos e na sobrevivência às péssimas condições em que se encontravam, o que está muito longe se constituir a obtenção de vantagem à qual a lei se refere.

A nomenclatura firma Hirata e Grillo (2017) faz equivalência entre facção e agente de mercados ilícitos (espécies de empresas do tráfico de drogas e armas), o que é insuficiente para nomear tudo que significa uma facção. 
Já o termo instituições de autorregulação do crime, cunhado por Silva (2020) apesar de estar baseado em uma leitura das facções enquanto fração de classe, que parece acertada, parece insuficiente ao introduzir uma ideia de autorregulação, que não parece ser o termo mais adequado para descrever a realidade dos grupos faccionais, que estão a todo momento sofrendo interferências por parte do Estado, bem como de agências sociais diversas, e tendo que adaptar-se ou resistir a elas.

Assim, a denominação facções brasileiras justifica-se pela junção: a) do termo facções para representar a divisão e heterogeneidade destes grupos; b) brasileiras por entender que a história destes grupos no contexto brasileiro possui suas especificidades, sendo incomparáveis a outras realidades nacionais.

\section{METODOLOGIA}

Para esta revisão integrativa, em junho de 202I foi feita uma primeira etapa de busca na base da dados SciELO, utilizando os termos (facções) OR (facção). Em seguida, realizou-se uma segunda busca, desta vez utilizando o termo (organizações criminosas). A escolha da base SciELO se justifica por reunir dados de periódicos interdisciplinares, como o é o objeto das facções. Já a opção de realizar duas buscas, pelos termos facções/facção e depois organizações criminosas, se deu por entender que, apesar de não ser a melhor denominação, muitos autores se referem às facções brasileiras através destes termos.

Os resultados da busca inicial pelos termos facções e facção, combinados, retornaram 7I registros. Já a busca pelo termo organizações criminosas retornou 22 artigos, totalizando um número inicial de 93 publicações de potencial interesse. Em seguida, procedeu-se a uma triagem, buscando eliminar artigos que não dissessem respeito ao tema do estudo. Esta seleção foi feita em três etapas, sendo a primeira delas a leitura do título do artigo, a partir da qual 43 artigos foram eliminados, seja pelo fato de serem artigos repetidos, por tratar de outros tipos de facções que não o objeto do presente estudo - por exemplo, facções políticas nacionais ou internacionais - ou mesmo por tratarem de outros assuntos não relacionados ao tema das facções.

A segunda etapa consistiu na leitura do resumo de cada artigo, a partir da qual i8 artigos foram excluídos por tratarem de temas não relevantes para a presente revisão. 
A terceira etapa consistiu na leitura do texto integral do artigo, visando confirmar a pertinência do artigo para a análise pretendida. Nesta etapa, houve a eliminação de 12 artigos, os quais citavam a existência de facções como um fenômeno que atravessava o objeto ou território de interesse do estudo, mas não trazia informações acerca das facções em si, ou mesmo por tratar de grupos que por vezes são considerados facções, mas de outros países que não o Brasil.

Em seguida, mais 3 artigos foram incorporados ao material selecionado, tendo sido encontrados através da leitura das referências dos artigos selecionados na busca inicial. Foram incluídos ainda, 8 livros completos publicados sobre o tema com a finalidade de realizar um mapeamento o mais completo possível do material já produzido na literatura sobre o tema.

\section{RESULTADOS E DISCUSSÃO}

O fluxograma a seguir ilustra o processo de seleção do material encontrado.

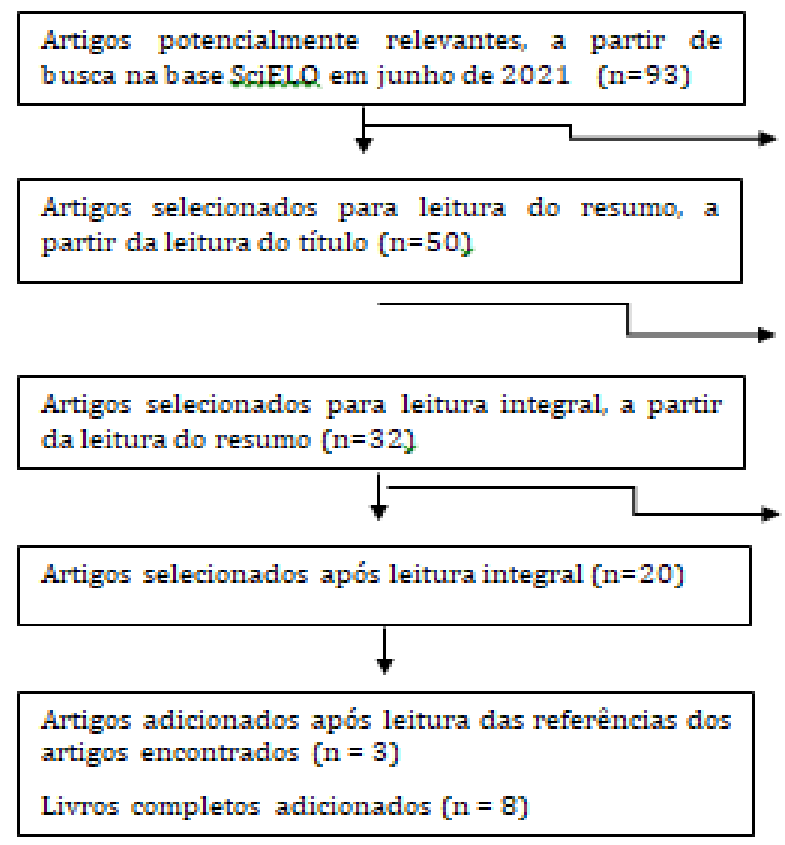

Eliminados pela leitura do título: repetidos; outros tipos de facções (facções políticas nacionais ou internacionais); temas alheios $(n=43$ )

Eliminados pela leitura do resumo: não relevantes para compreensão das facçóes $(n=18)$

Eliminados pela leitura integral: tema facçóes citado superficialmente; facçóes de outros paises, $(\mathrm{n}=12)$

Total de obras selecionadas $(\mathrm{n}=31)$ 
O número de obras que puderam ser selecionadas é bastante baixo, levando em consideração o período no qual se pode considerar que a história dos grupos faccionais remonta (primeiros coletivos prisionais do país remontam ao período de existência do Instituto Penal Candido Mendes - Ilha Grande, que passa a receber prisioneiros políticos na década de 1970).

Outra análise que pôde ser feita sobre o material encontrado diz respeito à regionalidade das facções discutidas nos artigos.

Gráfico I

\section{Distribuição das facções estudadas - por estado}

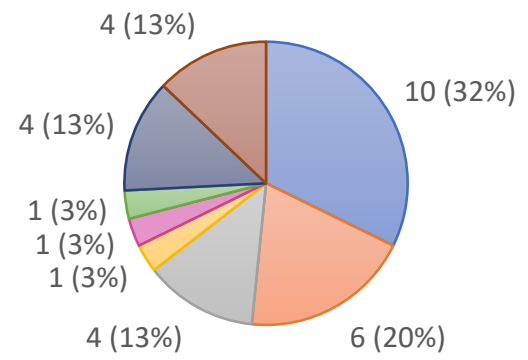

$\square \mathrm{RJ} \square \mathrm{SP} \square \mathrm{CE} \square \mathrm{AL} \square \mathrm{PA} \square \mathrm{RS} \quad \square \mathrm{RJ}$ eSP $\square$ Nacional

As facções do estado do Rio, de São Paulo e do Ceará constituem objeto de $65 \%$ dos estudos. Se, por um lado, tais números podem justificar-se pelo fato das facções cariocas e paulista terem sido as precursoras das demais facções nacionais, ou seja, possivelmente tendo sido estudadas desde mais cedo do que as facções de história mais recente, ao comparar tais dados à análise dos anos de publicação dos mesmos estudos, percebe-se que a quase totalidade dos estudos (97\%) é recente, publicados a partir de 2006 (Gráficos r e 2).

Gráfico 2
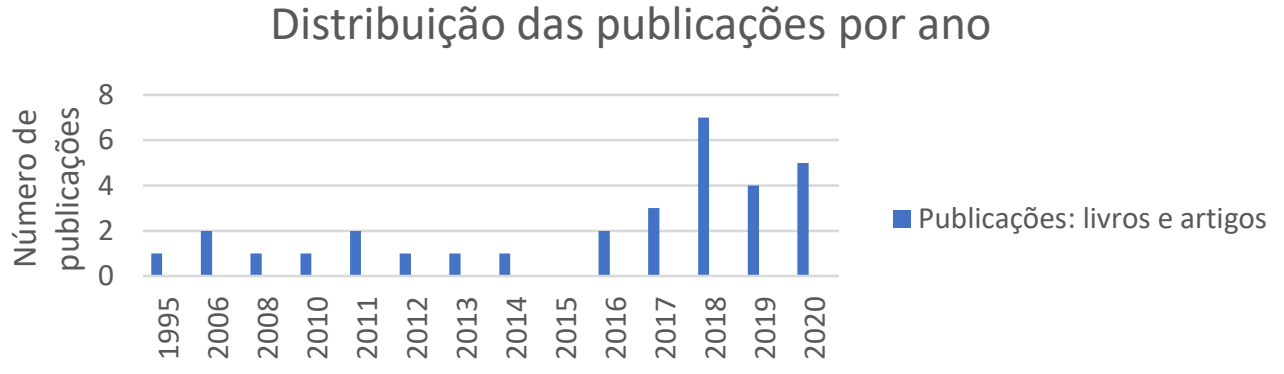
Uma hipótese para o lapso temporal existente entre a primeira publicação encontrada, que data de 1995 , sobre as facções cariocas e as demais publicações que, a partir de 2006 se mantiveram constantes ou em aumento, diz respeito ao processo de nacionalização das facções do sudeste, que gerou transformações na criminalidade local de vários dos estados do norte e nordeste do Brasil. O impacto destas transformações na criminalidade urbana é um determinante que possivelmente contribui para a mudança verificada no volume de publicações (Gráfico 2).

Quanto ao subtema que as publicações abordaram dentro do tema geral, 13 delas abordaram a relação dos grupos faccionais com o território no qual se inserem, 5 investigaram os mecanismos internos e organização das facções, Io discutiram eventos relacionados às facções nas prisões, I analisou a abordagem das facções em obras culturais, 3 exploraram a relação dos faccionados com as facções e 3 problematizaram as formas de análise do objeto das facções. Algumas abordaram vários temas simultaneamente.

\section{Gráfico 3}

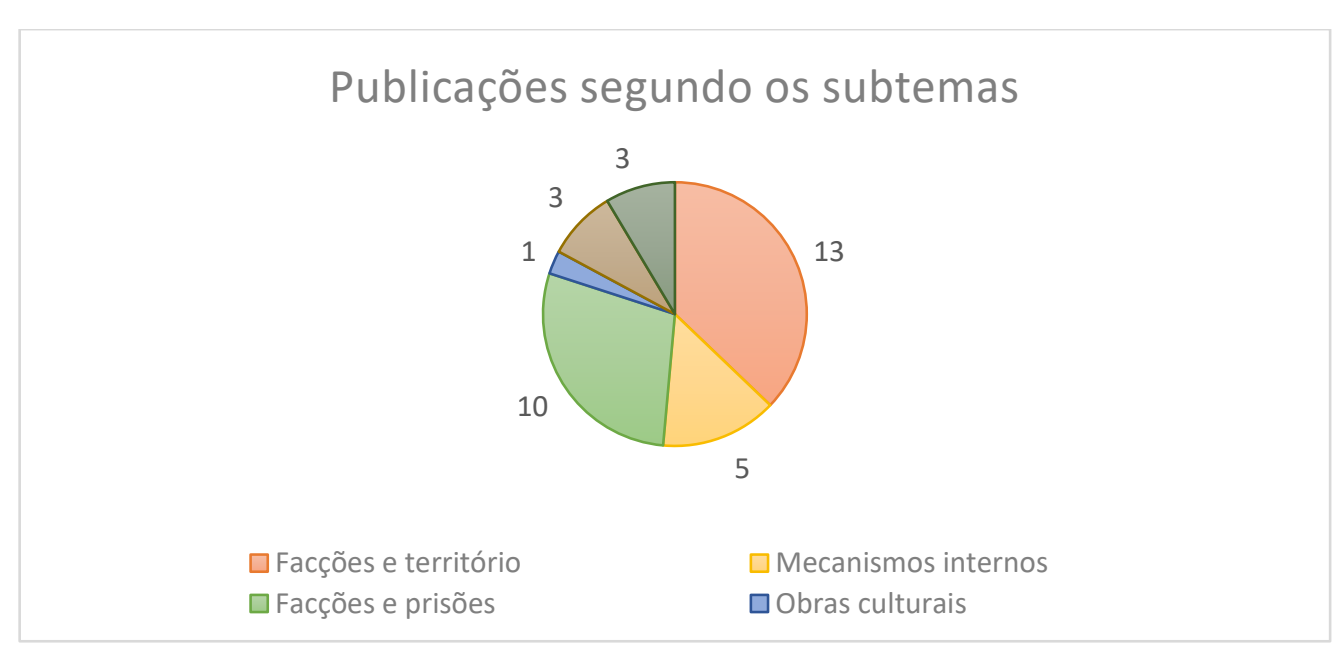

A partir da identificação destes focos de análise, as publicações selecionadas foram agrupadas em categorias temáticas, cuja discussão encontra-se a seguir.

\section{RELAÇÃO DOS GRUPOS FACCIONAIS COM O TERRITÓRIO NO QUAL SE INSEREM}

O estudo de Silva Filho e Mariano (2020), que buscou analisar o impacto da violência armada urbana de organizações criminosas no cotidiano de moradores e 
trabalhadores que atuam em uma periferia da cidade de Fortaleza, trouxe uma definição de "violência armada urbana" como um tipo de violência que ocorre em um "contexto de esgarçamento do tecido social”, não envolvendo, então, ações claramente motivadas por objetivos políticos, tais como protestos ou ações políticas armadas ou não, tampouco crimes que, apesar de envolverem violência, ocorrem com frequência em outros territórios e contextos, sem relação direta com o espaço urbano.

Ao abordar o incremento desta violência, os autores comparam períodos bastante pontuais de aumento e redução de homicídios em um curto espaço de tempo na cidade de Fortaleza. Trazem como uma das explicações para a diminuição das taxas de homicídio entre o final de 2015 e meados de 2016 a celebração de um acordo de paz entre as facções presentes na localidade, no qual se pactuou a proibição de vinganças e homicídios entre os grupos rivais. Após o rompimento deste pacto, as taxas de homicídio voltaram a subir. Outro reflexo da presença das facções nestes territórios, é de que a experiência de relações violentas, brigas, ameaças e homicídios foram vistas como rotineiras, integrando direta ou indiretamente a vida social (SILVA FILHO; MARIANO, 2020), conclusão corroborada no estudo de Benicio et al., (2018).

Além deste reflexo, perceberam que o processo de faccionalização dos territórios periféricos observados estabeleciam fronteiras invisíveis e dinâmicas, que separavam os moradores das localidades dominadas por facções rivais, restringindo sua circulação a territórios que não fossem dominados por grupos oponentes, independente da participação dos moradores nas atividades dos grupos faccionais (SILVA FILHO; MARIANO, 2020).

Noutro giro, denunciam a insuficiência de dados e informações oficiais que permitam mensurar e avaliar o efetivo impacto do conflito armado urbano sobre a rotina de moradores e trabalhadores de forma mais precisa. Este fato pode ser um desdobramento da dificuldade observada pelos autores por parte das autoridades estatais de admitir a existência e enxergar as ações destes grupos como uma questão a ser administrada pelo poder público. Uma importante consequência disto está na ausência de acompanhamento, por parte do Estado, da situação de moradores que têm sua liberdade de trânsito cerceada ou mesmo que são expulsos de suas residências. Para Silva Filho e Mariano (2020) então, os diagnósticos sobre violência armada urbana deveriam considerar os fatores sociais e 
econômicos do contexto no qual ocorrem, além de investigações sobre como se estruturam os grupos faccionais e sobre como estabelecem laços comunitários profundos.

Rui (2019), ao estudar as cracolândias das cidades do Rio e de São Paulo, discute, a partir de Frúgoli Jr. e Cavalcanti (2013 apud Rui, 2019), que o início da visibilidade da população usuária de crack no Rio se deu em função de sua expulsão das comunidades, pois os traficantes percebiam que sua presença ali atraía operações policiais. A partir de então, tais usuários passaram a transitar pela Avenida Brasil, podendo ser vistas por todos que passam por esta que é uma das principais vias da cidade. A autora relata ter presenciado, posteriormente, a realização de um acordo "entre a associação dos moradores, o CV e usuários, para que estes deixassem a Avenida Brasil e passassem a ocupar uma esquina da favela, a fim de fazer diminuir as incursões policiais" (p. 583).

Já Mattos (2016), a partir de estudo etnográfico realizado na favela da Nova Holanda, na capital do Rio de Janeiro, questiona a pressuposição naturalizada de que as favelas seriam ao mesmo tempo, lócus e causa da "violência urbana" (p. II). A partir de relatos acerca de como sucessivas lideranças locais estabeleceram estratégias para mediação de conflitos no território, de confrontos com uma facção rival ou com a polícia, a autora demonstra como aquilo que chama de "governos locais" (p.II), governos externos e políticas de segurança pública são partes integrantes de um mesmo ordenamento. Considera ainda que o confronto de facções e a atuação de Caveirões seriam estratégias complementares, que permitiriam a sustentação de uma rede complexa capaz de coproduzir a ordem da favela estudada, gerando efeitos que reverberariam pela cidade como um todo.

O artigo de Raposo (2014) traz recortes de cenas que analisam códigos de conduta adotados por moradores de regiões dominadas por diferentes facções na Favela da Maré. Um dos fatos que lhe chamavam a atenção dizia respeito a alguns moradores que trabalhavam para o tráfico andarem com armas pelo bairro, o que era tratado com naturalidade pela vizinhança, não significando, no entanto, que concordassem com aquilo. De acordo com um dos entrevistados, andar com as armas em exibição, além de ser um jeito encontrado pela facção local para afirmar seu poder diante dos moradores, possuía um valor simbólico muito além daquele ligado ao próprio uso da arma, como uma 
demonstração de poder de guerra que desencoraja invasões de facções inimigas. Esta análise é corroborada no artigo de Zaluar e Barcellos (2013), para quem o aumento das taxas de homicídio nestes locais é muito mais explicado pela alta concentração de armas nestes locais do que por "uma inclinação natural dos homens jovens pobres à violência" (p.22).

Acerca das práticas regulatórias originadas nas facções, Raposo (2014) cita as proibições de roubar e estuprar na favela, práticas severamente punidas pelos líderes da facção. Além destas, a prática de "xisnovar", literally "exnining”, from the term "X-9" (p.29) é a pior transgressão no sistema de socialização das facções, muitas vezes punida com a morte. Outras práticas observadas, desta vez menos explícitas, dizem respeito a códigos de linguagem e vestuário, que demarcavam diferenças entre as facções que compunham os territórios da Maré. Enquanto a expressão "é nós” só podia ser utilizada por membros ou moradores de áreas controladas pelo CV, “é a gente” deveria seu utilizada por membros do TCP ou ADA. Da mesma forma usar uma camisa vermelha (cor associada ao Comando Vermelho) em uma favela dominada pelo ADA ou pelo TCP poderia ser seriamente perigoso (RAPOSO, 2014). Este é outro exemplo de regras datadas, que rapidamente se modificam na trajetória histórica das facções e que hoje não mais se verifica.

Passando ao contexto cearense, Paiva (2019), ao analisar as transformações nas práticas criminais em Fortaleza, recupera as condições históricas que possibilitaram o surgimento de facções locais. O contexto das periferias de Fortaleza na década de 1990 comportava a existência de gangues, como eram denominados grupos de jovens que compartilhavam modos de sociabilização e que se reuniam publicamente para demonstração de forças. Tais gangues se reuniam nas ruas ou bailes funk para brigar, trocar pedradas ou pauladas. Posteriormente ocorreu a chegada de armas e drogas nas periferias, num contexto cuja prioridade não foi a de formação de mercados ilegais, mas sim de incremento nas disputas territoriais entre as gangues.

A partir de 2014, traficantes locais começaram a aventar uma possível união, "com reuniões dentro e fora dos presídios para discutir arranjos que envolviam as facções PCC, CV e FDN” Paiva (2019, p.173). A ocorrência destes arranjos é, provavelmente, reflexo do 
movimento de nacionalização das facções cariocas e paulista, citada por diversos dos estudos encontrados (AMORIM, 20II) (AMORIM, 2006) (MISSE, 20II). Para Misse (20II), não só o modelo do tráfico, mas o do jogo do bicho e o das milícias cariocas também teriam sido adotados em outros estados brasileiros, "nacionalizando formas de organizações criminosas que têm no recurso à violência uma de suas principais características" (p.13).

Por outro lado, o surgimento de uma facção local em 2016, os Guardiões do Estado (GDE) demonstra a existência de grupos resistentes à chegada das "facções de fora" e dispostos a reunir-se sob outros acordos de sociabilização, a exemplo do que ocorre com a criação do Sindicato do Crime (SDC), no Rio Grande do Norte, além da facção Família do Norte (FDN), que se constituiu no interior do sistema prisional amazonense, sustentandose em esquemas nacionais e internacionais de tráfico de drogas e reivindicando o domínio do crime naquela região. O próprio nome Guardiões do Estado é revelador desta dimensão de defesa contra o domínio das facções advindas de outros estados, que se refletiu na formulação de maneiras próprias de gerir seus filiados, garantindo a estes a participação em decisões coletivas e não fazendo cobranças de mensalidade. Manifestações públicas de seus integrantes apontam ainda para a tentativa de demarcar uma diferenciação com as gangues que antigamente habitavam aqueles territórios: “[...] tempo das gangues em Fortaleza acabou, agora é facção e todos têm que respeitar” (p. 170). Paiva (2019) destaca, então, a criação da facção GDE como um ponto crucial na compreensão das transformações que as práticas criminais tiveram em Fortaleza, uma vez que foi em função dela que importantes alianças e resistências se formaram, no complexo jogo de rivalidades que permeia a região.

Já sobre a realidade paulista, Feltran (2012) formula a tese de que as políticas públicas de controle da violência letal em São Paulo (ao menos no período analisado) são forjadas a partir de uma dimensão relacional entre governo (no sentido do que é originário da burocracia do Estado) e crime, que não pode ser ignorada ou encarada equivocadamente como constituída de estratégias sempre opostas e antagônicas.

$\mathrm{O}$ autor indica o dia 2 de outubro de 1992 como emblemático para uma mudança ocorrida tanto nas políticas estatais de gestão da violência quanto naquelas produzidas pelo 
crime. Por um lado, a repercussão que teve o evento que culminou com as III mortes de encarcerados gerou mudanças na política de gestão penitenciária, até então baseada no suplício. Por outro, os presos passaram a entender a ajuda das pastorais carcerárias na transmissão de suas reivindicações como insuficientes, tornado insustentável a manutenção desta parceria como fonte principal de aposta dos presos na busca por seus direitos a um tratamento minimamente digno. Além disto, os conflitos que há tempos vinham permeando a convivência entre os presos - as injustiças na relação entre eles mesmos e as opressões que sofriam por parte do sistema - se intensificaram de modo a fugir completamente do alcance de intervenção dessas organizações.

Além destes fatores, a legitimação pela massa carcerária foi fator fundamental para o processo de expansão do PCC e pelo estabelecimento de regras para o convívio e proibição do uso do crack nos presídios sob a ordem da facção. Além deste processo, o resultado das disputas contra facções rivais ou entre ideologias divergentes dentro do próprio PCC consolidaram a autoridade e a hegemonia do "Partido" na maioria das prisões paulistas, sendo a megarrebelião de 2001 (que somou 26 unidades prisionais paulistas) o ritual de consolidação dessa hegemonia (FELTRAN, 2012).

Como reposta a este evento, é instaurado o Regime Disciplinar Diferenciado (RDD), que adota a estratégia de isolamento de lideranças da facção e dificulta o exercício destes papéis hierarquizados de poder. Com isto, o regime acaba contribuindo para que o ideal de igualdade restasse amplamente fortalecido no PCC (FELTRAN, 2012).

Os grandes eventos de demonstração de força da facção que ocorreram, dentro e fora dos presídios em 2006 gera, por parte do governo, a reposta de um massacre prisional. Verifica-se, em seguida, um novo armistício que, operando em conjunto com novos acertos, ainda que conflituosos entre "indivíduos inscritos no governo e no crime [...] faz com que a diminuição dos homicídios em São Paulo se estabilize em queda importante até 20II" (FELTRAN, 2012), p. 248).

Cuervo Ceballos (2018) por sua vez, ao discutir as relações no crime organizado transacional, considera que o PCC e o CV são grupos que teriam levado o terror para a Tríplice Fronteira (formada por Argentina, Paraguai e Brasil), provocando mortes e instabilidade na região através de disputas por domínio territorial de rotas do tráfico e 
vinganças. Já Sampó, Quirós e Petrino (2020) consideram que o crime organizado se valeria de duas ferramentas para garantir sua sobrevivência e reprodução. De um lado, o uso da corrupção na relação com o Estado, buscando flexibilizar o controle e garantir proteção contra perseguições, prisões e condenações. De outro, o uso da violência direta ou indireta - ameaças, cobrança de pedágios, expulsões residenciais, ferimentos e homicídios intencionais - objetivaria a eliminação da concorrência nos mercados ilegais, a manutenção da subordinação de seus integrantes e o máximo afastamento possível do Estado do território controlado por elas.

Como se pode constatar, os artigos desta categoria puderam tratar da relação das facções com o território em diversos dos estados brasileiros, além da relação com algumas das autoridades de segurança e políticas de segurança pública.

\section{MECANISMOS INTERNOS E ORGANIZAÇÃO DAS FACÇÕES}

Hirata e Grillo (2017) acabam por perpassar o tema das facções em seu estudo, que constitui em uma análise comparativa entre o funcionamento dos mercados ilegais de venda de drogas nas cidades do Rio de Janeiro e de São Paulo. Esta relação entre os facções e tráfico encontra apoio na leitura dos autores que, concordando com Barbosa (2005 apud Hirata e Grillo, 2017), entendem que o tráfico teria reunido e organizado o campo dos ilegalismos populares de maneira peculiar, fazendo com que as demais práticas criminais relacionadas assumissem posição secundária em torno de suas demandas, embora em São Paulo o roubo ainda ocupe uma posição de centralidade que é ressalvada pelos autores.

Os autores fazem uma remissão histórica que informa sobre as origens comuns (embora afastadas temporalmente em quase 20 anos) das facções e comandos de Rio e São Paulo a partir dos coletivos que se organizaram no interior do sistema prisional objetivando a organização da convivência entre os presos e a criação de estratégias de comunicação com a administração prisional. No entanto, apesar deste ponto análogo e do fato de que ambos estabeleceram o tráfico de drogas como principal fonte de subsídio financeiro, a maneira como este mercado ilegal - o movimento - se desenvolve no interior das diferentes facções é muito diferente. 
Para compreender esta diferença, é necessário considerar que em São Paulo o Primeiro Comando da Capital - PCC conseguiu se consolidar como facção hegemônica, enquanto no Rio, desde muito cedo grandes grupos faccionais disputam o domínio de territórios nas prisões e nas favelas da cidade. (HIRATA; GRILLO, 2017).

Observando estas discrepâncias entre heterogeneidade faccional aliada às políticas de segurança pública de confronto territorial e de ocupação policial adotadas no Rio, e de hegemonia faccional e encarceramento em massa adotados em São Paulo, fica mais fácil compreender o estabelecimento de táticas e postos de defesa territorial armada adotadas no contexto carioca, "contribuindo para que se disseminasse o porte ostensivo de armas de fogo nas "bocas de fumo" e traficantes reivindicassem o poder de vigilância e punição em seus domínios" (p. 8I). O emprego dos "soldados" (p. 8I), que realizam a defesa dos territórios da facção contra as investidas armadas de facções rivais ou das polícias é uma característica importante na diferenciação da dinâmica interna das firmas cariocas e dos comandos paulistas (HIRATA; GRILLO, 2017).

Outra diferença importante refere-se aos "princípios de 132 inclusividade/exclusividade dos comandos" (p. 85). No PCC, aqueles que se tornam “irmãos” passam a ser assim chamados após passar por um "batismo”. Como decorrência desta relação de "pertencimento", nos períodos em que estiverem fora da prisão, devem contribuir com pagamentos mensais ao "Partido" (Dias, 2013 apud Hirata e Grillo (2017), enquanto para as facções cariocas não há protocolo estabelecido de adesão de seus membros. Ocorre ainda que, no Rio de Janeiro, qualquer morador de uma área que seja dominada por determinada facção, seja ele envolvido ou não com o tráfico local, pode evocar o pertencimento a ela.

Dentre as muitas diferenças que os autores conseguem identificar, destaca-se aqui, finalmente, uma que diz respeito às consequências das alianças, traições e rupturas que por vezes ocorrem entre os grupos faccionais. Se, por um lado, os autores identificam a hegemonia do PCC em São Paulo como fonte de pacificação e o inverso ocorrendo no Rio, apresentam como hipótese a ser trabalhada a de que, no caso do Rio, as rupturas internas ou alianças com outros grupos seriam mais raras, porém de maior impacto na estrutura dos comandos, enquanto em São Paulo, as dissidências e rompimentos nas alianças teriam 
maior frequência, embora gerando consequências muito menores na estrutura (HIRATA; GRILLO, 2017). É uma hipótese importante a ser investigada por estudos futuros.

Lessing (2008) também compara as trajetórias do mercado de drogas, mas desta vez entre as cidades do Rio de Janeiro, São Paulo, Recife e Porto Alegre, buscando compreender o que poderia justificar a percepção largamente difundida de que os mercados cariocas constituiriam um fenômeno sui generis, incomparável ao de qualquer outro território. Segundo ele, a diferença entre o Rio e as demais cidades não estaria relacionada nem às tendências de formação e expansão de territórios controlados - que seria uma espécie de traço universal destas organizações - nem no comportamento de seus respectivos membros, mas sim no sucesso que as organizações cariocas têm ao resistir às forças que tentem fragmentá-las ou exterminá-las. Além disto, o fato de o comércio de drogas ter sido controlado desde cedo pelos mesmos grupos que também dominavam as prisões do estado "ajudou a neutralizar essas forças fragmentadoras, permitindo o estabelecimento de um equilíbrio surpreendentemente estável num nível alto de concentração" (p. 45), o que seria um diferencial das facções cariocas. Esta é uma hipótese importante a ser investigada em estudos futuros, constituindo uma importante contribuição trazida pelo autor.

O livro de Bill e Athayde (2006) "Falcão - meninos do tráfico" traz pistas importantes sobre algumas das determinações que são ignoradas nos estudos que reduzem as facções ao tráfico. Apesar de não ser exatamente uma obra científica - possui caráter exploratório, jornalístico, além de o juízo de moralidade dos autores ficar bastante evidente, tanto na narrativa como no processo de entrevistas transcrito em alguns trechos - pode ser considerado pioneiro ao, junto com o documentário homônimo, alcançar visibilidade inédita até então.

Bill e Athayde (2006) apresentam ao leitor aspectos da dinâmica interna das facções, a exemplo das funções exercidas por seus funcionários. O fiel seria o cargo de meninos (geralmente crianças, em um primeiro momento de aproximação com os funcionários do tráfico) que faziam favores para os faccionados, como comprar lanches, cigarro, entre outros, em troca de pequenas quantias ou ajudas diversas. $\mathrm{O}$ atividade, sinônimo de falcão, aquele que vigia, protege as bocas; o fogueteiro, aquele que dispara fogos 
de artifício para avisar sobre a chegada de policiais na favela; o vapor, aquele que vende as drogas no varejo aos clientes. Outros personagens importantes seriam os $X-9$, que ligariam para a polícia passando informações privilegiadas sobre o paradeiro de drogas, armas ou funcionários do tráfico nas favelas.

Também é citada, embora brevemente, a existência das milícias, na época chamadas de mineiras pelos adolescentes entrevistados, bem como a dimensão de relacionamento entre as milícias, as facções e os moradores das comunidades dominadas por um ou outro grupo (BILL; ATHAYDE, 2006).

Já especificamente sobre o PCC, o livro de Feltran (2018), “Irmãos”, aborda a facção compreendendo-a como um fenômeno que estaria muito mais próximo de uma relação de irmandade entre os que teriam algum tipo de relação com ela do que como uma organização de lógica empresarial ou de cartel. O autor destaca, ainda, que há múltiplas formas de relacionar-se com o PCC, diante das quais as concepções de pertencimento ou envolvimento, comumente utilizadas para referir-se a sujeitos que compões tais relações são insuficientes. As expressões correr com o Comando ou correr com o PCC podem significar variados e multifacetados níveis de relações que são discutidas de uma maneira atenta e cuidadosa pelo autor.

Em trabalho anterior, Feltran (2010) propõe a existência de uma "ética" e de uma "lei” específicas do mundo do crime, que comportariam dispositivos próprios para mediação e resolução de determinados tipos de conflitos envolvendo moradores das periferias ou pessoas "inscritas no crime" (p.63). Enquanto dispositivo analisador, o autor elegeu os "tribunais do crime”, composto por um debate para julgamento, no qual entrariam em jogo as performances e depoimentos de acusados e vítimas, que teriam espaço para amplas argumentação e defesa, sendo esta uma prática institucionalizada no cotidiano dos territórios onde há a presença do PCC.

Nesta seção, os artigos selecionados realizaram analogias entre facção e mercados ilícitos, comparações entre os mecanismos internos de facções de diferentes estados brasileiros, exposição acerca dos cargos que são criados no interior das facções para a venda de drogas, bem como análise de dispositivos específicos de facções, como os tribunais do crime. 


\section{AS FACÇÕES NAS PRISÕES}

A relação das facções com as prisões é tema da mais alta relevância. As primeiras obras a tratarem disto não possuíam caráter científico, mas sim jornalístico ou literário e são responsáveis por resgatar relatos históricos fundamentais para o estudo das facções brasileiras.

Os livros de Amorim (2006; 2011), e Lima (2016) são obras que abordam o período de convivência entre os presos políticos do período da Ditadura Militar no Brasil e os presos "comuns" que, por realizarem assaltos a bancos eram enquadrados na mesma Lei de Segurança Nacional criada no período. Enquanto dois grupos distintos de criminalizados, tinham em comum atos que desrespeitavam as instituições e a soberania nacional, de acordo com os julgamentos da Justiça Militar. Portanto, suas prisões não possuíam apenas o caráter de pena, mas também de humilhação e de demonstração da autoridade MilitarEstatal e, por isto, tais prisioneiros eram enviados para cumprir suas penas em um presídio isolado, de difícil acesso e que dificultava tanto a comunicação com o mundo exterior como a percepção, pela sociedade, das graves violações de direitos às quais os internos eram submetidos durante sua estadia ali.

Já o livro "40o contra I: uma história do Comando Vermelho" de Lima (2016) é um livro escrito do ponto de vista de um dos presos "comuns" que esteve na Ilha Grande. Conhecido também como "Professor", Willian da Silva Lima, recentemente falecido no Rio de Janeiro, foi considerado o último sobrevivente do grupo de "Fundadores do Comando Vermelho".

Varella (2017), por sua vez, transcreveu importantes relatos ouvidos no interior de algumas Casas de Detenção do estado de São Paulo. Através destes, constata-se que as condições materiais impostas pela experiência do encarceramento em prisões brasileiras são um fator intimamente ligado ao surgimento das facções, o que demonstra a necessidade de aprofundar os estudos (anda muito tangenciais) sobre as relações entre facções e prisões, ou entre facções e condições para o cumprimento de penas em cadeias brasileiras. Segundo Manso e Dias (2018), a política do encarceramento em massa teria sido responsável por promover ou facilitar a organização dos mecanismos do tráfico a nível inédito, produzindo um fenômeno que não só permeia as mais de 1.400 prisões 
brasileiras, mas as extrapola em direção às periferias, evidenciando o inédito intercâmbio entre os territórios intra e extramuros.

Em seu livro “Irmãos: uma história do PCC”, Feltran (2018) recupera uma entrevista de Marcola para a CPI do Tráfico de Armas em 2006, na qual ele pode dar sua própria versão sobre as Revoltas ocorridas no contexto faccional naquele ano. Segundo ele, as revoltas eram fruto da insatisfação dos próprios presos com o modo como as lideranças vinham sendo tratadas, e não por uma ordem hierárquica superior, pois há tempos o PCC já não funcionaria mais sobre esta lógica de comando. Apesar de ter sido chamado em 2001 para realizar um acordo de apaziguamento dos presídios - bem sucedido - após ser chamado pelo governo para realizar um novo acordo em 2006, já não se considerava mais capaz de tanto, pois não ocupava mais nenhuma posição política no Comando. Para o autor, a adesão dos presos à lógica mais igualitária de Marcola facilitou os acertos monetários com a polícia, abrindo um caminho para que o dinheiro atuasse como mediador dos conflitos, o que teve papel inegável nos fatos sobre os quais a disputa narrativa se dá, incluindo a redução dos homicídios no Estado naqueles períodos.

Já o estudo de Nascimento, Marques e Osterne (2020) discute as normas e os limites estabelecidas para a convivência de presos identificados como LGBT em presídios do Ceará. A partir das rebeliões ocorridas em maio de 2016, os grupos faccionais presentes no Estado ganharam maior visibilidade e as relações de filiação dos presos aos grupos faccionais envolvidos provocaram sua realocação pelos presídios da região. Além da separação de acordo com a filiação às facções presentes no Ceará, Primeiro Comando da Capital (PCC), Comando Vermelho (CV), Guardiões do Estado (GDE) e Família do Norte (FDN), o Estado precisou providenciar a criação de novas unidades para acautelar aqueles que não se filiavam a nenhum destes grupos e, por isto, ficavam em uma situação de vulnerabilidade que demandava alguma medida de proteção. Além destes, estas unidades abrigavam ainda os condenados por crimes sexuais e a população LGBT, também considerados em situação vulnerável na dinâmica prisional. Outras consequências do período rebelional de 2016 foram a destruição total ou parcial das estruturas internas de presídios, ataques a ônibus e delegacias, greve dos agentes penitenciários exigindo melhorias salarias e de condições trabalhistas, além de reflexos diretos na vida das bichas 
(como são chamados pelos presos os homossexuais, bissexuais, travestis e transexuais) e os artigos errados, ou seja, os condenados por crimes sexuais.

Ainda sobre acordos de convivência prisional, Manso e Dias (2018) abordam as relações entre os presos nos períodos em torno do "racha" (p.7) ocorrido em 2016, ou seja, o rompimento da aliança formada entre O Comando Vermelho e o Primeiro Comando da Capital. A partir desta cisão, os presos pertencentes às respectivas "siglas" (p.9) passaram a ser chamados de encurralados quando se encontravam em presídios dominados pela sigla agora rival, por exemplo, os presos do CV-MT em Mato Grosso do Sul; os presos do PCC em Mato Grosso" (p.9). Passando a sofrer todo tipo de pressão e ameaças, estes presos agora precisaram ser realocados em celas de seguro em uma unidade prisional também de seguro. Mesmo que estes presos não cumprissem os requisitos que normalmente são os motivadores para a separação em unidades de seguro, tais como ter cometido crimes sexuais ou estarem jurados de morte pelas ordens faccionais, a convivência com os demais presos agora de facção rival - se tornou insustentável, o que justificou a necessidade da separação entre eles e os demais. Isto gera uma situação especificamente mais complicada pois a alocação em grupos de seguro tem um impacto na moral e nas relações prisionais, colocando os sujeitos ali alocados numa "condição tida como humilhante para um preso com sua trajetória e posição no crime" (p.9).

A partir das percepções dos agentes territoriais da segurança pública nos presídios do Pará, Netto e Chagas (2019) consideram que a criação de tais redes de cooperação e expansão das facções seria facilitada pela transferência de presos feita de maneira inadequada, misturando presos provisórios ou não e indiciados por diferentes delitos, além da transferência intermunicipal ou interestadual.

Além disto, os entrevistados consideram que algumas ideologias falaciosas seriam utilizadas pelas lideranças em seu discurso para arregimentar membros para a facção, numa prática de "enganação" que enxerga os faccionados como figuras ingênuas e chama atenção pela simplificação a que os sujeitos entrevistados reduzem o complexo fenômeno das facções.

Também partindo do ponto de vista de agente de segurança prisional, o artigo de Schabbach e Passos (2020) identifica no ano de 1987 a confirmação da existência do grupo 
Falange Gaúcha (em alusão à Falange Vermelha, nome do coletivo prisional que deu origem ao Comando vermelho), que os autores apontam como sendo a primeira organização criminal reconhecida da capital do estado. A facção seria desdobramento de um pacto celebrado entre assaltantes de banco e traficantes de drogas de dentro e de fora das prisões, que estabelecia a criação de um fundo para o financiamento de fugas, compra e revenda de drogas, bem como de vantagens no interior dos presídios.

Com a expansão dos grupos faccionais, o consequente aumento dos roubos ao comércio e dos confrontos entre as facções na década de 1990 (dentro e fora das prisões), em 1994 é celebrado um acordo entre os presos e o governo estadual, objetivando a cessação das fugas e rebeliões, em troca que envolvia a não realização de fugas e motins em troca de mudanças nas regras de segurança. Com o passar do tempo, a situação nas prisões se torna pior e aumentam as denúncias de corrupção e maus-tratos aos presos, diante do que o governo estadual resolve transferir a direção de quatro prisões e do Hospital Penitenciário para a Brigada Militar - Polícia estadual no Rio Grande do Sul, estratégia que permanece sendo adotada até hoje na administração penitenciária no estado (SCHABBACH; PASSOS, 2020).

O estudo de Godoi (2017) observa que a dinâmica do sistema penitenciário engloba um fenômeno marcado pela inércia processual, de modo que só há movimentações processuais quando é tomada alguma iniciativa junto ao Poder Judiciário por parte dos presos, de seus defensores públicos ou particulares. Ocorre que, para a tomada de tais iniciativas, faz-se necessário o estabelecimento de redes de solidariedade ou de cooperação com contrapartidas diversas, seja pela ajuda de um companheiro de presídio que escreve cartas ou pedidos ao Poder Judiciário, familiares que que contratam advogados ou outros agentes. Para a formação destas redes de cooperação, o apoio do PCC muitas vezes se faz imprescindível e iniciativas de assistência jurídica - como o custeio de advogados particulares para atendimento de membros e aliados da facção - já não constituem mais práticas que privilegiam pequenos grupos de presos. Nesta leitura, tais práticas cooperativas no interior do PCC representariam reações coletivizadas às exigências que a própria maneira como o sistema penitenciário tem gerido seus presos e sua situação processual impõem aos apenados. $\mathrm{Na}$ medida em que eles próprios precisam conseguir 
meios de saber sobre seu processo e fazê-lo "andar", o estabelecimento de relações com a estrutura faccional se torna um meio de obter recursos na luta por sua liberdade (GODOI, 2017).

Nesta seção, pode-se constatar como as condições materiais para o cumprimento de penas nos presídios brasileiros são relevantes para o surgimento e manutenção das facções. Muitas das obras discutidas aqui não possuem caráter científico, mas são livros que trazem relatos fundamentais para um resgate histórico acerca dos períodos iniciais de formação destes grupos.

\section{ABORDAGEM DAS FACÇÕES EM OBRAS CULTURAIS}

O artigo de Lessa e Souza (2020) baseia-se na análise de quatro músicas do grupo de Rap Facção Central - Eles vão ter que algemar meu cadáver; Quando Eu Sair Daqui; O Espetáculo do Circo dos Horrores; Estrada da Dor 666. Utilizando o método da análise crítica do discurso, buscam verificar como a violência policial é retratada nas canções de rap.

Para os autores, a violência praticada por agentes estatais enquanto mecanismo de controle constitui uma estratégia fundamental para a efetivação do capitalismo e da necessária desigualdade social que ele provoca (LESSA; SOUZA, 2020). Destacam a centralidade dos temas da violência, desigualdade e discriminação nas letras, além da revelação de um antagonismo entre os protagonistas citados nas letras (policiais versus detentos, criminosos e pobres), que contribuem para formação de uma lógica "nós versus eles" retratada nas obras a partir da perspectiva dos cantores. Como consequência, esta violência é identificada pelos autores como uma espécie de "cimento social” (p. 208) que forma e mantem coesas as relações entre os grupos violentados que se solidarizam em rede contra a violência policial.

Sendo a única seção que possui apenas um estudo que, por sua vez, parte do ponto de vista dos faccionados que elaboram as canções estudadas, esta nos permite vislumbrar como as condições materiais da vida nas periferias e a maneira como as polícias tratam os que ali residem contribuem para a formação de uma lógica "nós versus eles". A existência desta lógica escancara uma dinâmica velada, na qual a população é vista como inimigo pelo 
Estado, ou ao menos por suas políticas de governo que, até hoje, perpetuam a lógica do inimigo aplicada em diversos momentos de nossa história, em alguns deles de forma declarada, tal como verificou-se no período da Ditadura Militar no Brasil.

\section{A RELAÇÃO ENTRE OS FACCIONADOS E A FACÇÃO}

Rodrigues (2020) nos informa da existência de uma a crescente polarização entre grupos identificados ao PCC e ao CV em Alagoas. A partir de 2014, as instituições para cumprimento de medida de internação passam a sofrer pressão de lideranças faccionais para que os adolescentes internados fossem separados de acordo com suas identificações ou simpatia por uma das facções, sendo tal ordenação adotada como referência de gestão no sistema socioeducativo em 2or6. A partir desta divisão, surge uma terceira posição que, não obstante não se referir como faccional, se autorrefere como "do crime". Esta realidade aponta para a existência de grupos contra-hegemônicos que tensionam a dominação gerada pelo processo de nacionalização das facções do Rio e de São Paulo.

Outra determinação importante dente tensionamento, identificada por Rodrigues (2020) diz respeito às desigualdades no acesso a poderes econômicos e simbólicos criminais entre os faccionados de Rio-São Paulo e dos heterogêneos estados no Nordeste. Assim, "ainda que as identificações PCC e CV expressem padronizações entre práticas criminais e moralidades locais, nacionais e internacionais" (p. 3), nas regiões para as quais as facções se expandem, são formadas dinâmicas de poder e arranjos de sociabilização diversos daqueles dos territórios onde surgiram.

Além disto, a existência das dissidências para com os grupos faccionais com os quais tinham que conviver nos alojamentos no sistema socioeducativo gerava tensões, ou, como descreve Rodrigues (2020), os dissidentes acabavam "perdendo o convívio" (p. 9). Tais tensionamentos geraram não apenas a necessidade de se afastar da facção através da adoção de uma outra maneira de se autorreferenciar, como a criação pelo Estado, de outras unidades para abrigar estes novos grupos de adolescentes.

Por outro lado, as relações entre facções e Estado muitas vezes se mantêm, como é o caso dos fenômenos de pacificação que ocorrem quando há acordos entre lideranças faccionais (entre si ou com agentes estatais), mas que são reivindicados pelos governantes 
como efeito de suas políticas de segurança pública. Assim como relata Feltran (2018) ter ocorrido no estado de São Paulo, Rodrigues (2020) aponta que o governo do estado de Alagoas tem tomado como mérito próprio a redução nas taxas de homicídios no estado, ignorando os efeitos do zoneamento faccional demarcado entre CV e PCC em 2016.

Hernández et al. (2018) por sua vez, investigam as dimensões de paternidade na trajetória de adolescentes em cumprimento de medida socioeducativa de internação, identificando que na vida de muitos deles as facções têm importante papel na construção de masculinidades. Um dos entrevistados, que divide as despesas da criação do filho com a mãe da criança, explica que esta trabalha em uma casa de família, com carteira assinada e que ele entrega cerca de 600 ou 700 reais para ela. Como agora ele está internado na unidade, a facção à qual ele pertence é quem está provendo esta quantia para ela, segundo o adolescente, "pela minha postura na boca de fumo" (p. 75).

Foram encontrados relatos, tanto de que a paternidade funcione como um motivo para deixar o tráfico ou as práticas criminosas, como os de que o envolvimento nas facções é o que possibilita que o adolescente possa oferecer sustento e certo status aos filhos, por mais breve que esta garantia seja, em alguns casos, considerando uma possível morte ou encarceramento deste pai. Também aparece em alguns relatos, a preocupação do adolescente com seu envolvimento no tráfico e a necessidade de "dar um bom exemplo" (p. 78) para os filhos. (HERNÁNDEZ et al., 2018).

Esta seção traz relatos sobre como os próprios facionados se referenciam enquanto pertencentes ou não a um grupo faccional, além de dar pistas sobre algumas das dimensões de sociabilidade que envolvem tal pertencimento, tais como os referenciais de identidade, ideais de masculinidade ou de paternidade.

\section{META-ANÁLISE: ABORDAGENS ACERCA DAS FACÇÕES}

$\mathrm{O}$ artigo de Aquino e Hirata (2018) constitui uma espécie de revisão sobre trabalhos de mestrado e doutorado sobre o tema da criminalidade em geral. Embora não se debruce especificamente sobre o objeto das facções, alguns dos estudos discutidos abordam o crime e seus protagonistas, o que, por vezes, implica na relação com alguma facção. Considerando este um campo de estudos em construção (P.13o), os autores apontam a importância das pesquisas etnográficas sobre o tema da criminalidade, que têm 
representado um ganho enorme para as ciências sociais no Brasil ao construir conhecimento acerca do fenômeno do crime, suas dinâmicas e personagens.

Já a exposição de Misse (1995) lista cinco teses que identifica na literatura acerca da criminalidade urbana, entendendo-as como equivocadas. A primeira tese equivocada seria: a pobreza é a causa da criminalidade urbana, ou do aumento da violência urbana; a segunda: o bandido das áreas urbanas pobres é um herói e justiceiro, que rouba dos ricos para dar aos pobres; a terceira: a criminalidade urbana no Rio é descendente direta dos quilombos, das "estratégias de resistência" de negros e mulatos nos morros e favelas, na "ética da malandragem" (p. 8); a quarta: o migrante rural tradicional, geralmente nortista ou nordestino, inadaptado nas grandes cidades e lançado à miséria e ao isolamento dos vínculos comunitários, em geral ocupando funções desqualificadas em áreas como a construção civil, é o personagem central da violência urbana; e a quinta: o aumento da criminalidade violenta é uma dimensão do aprofundamento da luta de classes.

Já o livro de Biondi (2018), apesar de ter como foco discutir território, hierarquia e lei no PCC, traz discussões interessantes sobre o próprio método adotado em sua 142 investigação. Tecendo críticas a proposições acerca da suposta necessidade de um esforço positivista para o estudo de fenômenos com o PCC, através da coleta de dados junto a outros atores, externos a ele, a autora argumenta que dados acessados junto a outros atores nada revelam sobre o PCC, mas sim sobre as reflexões que estes atores tecem a respeito dele" (p.34), o que não garantiria a neutralidade exigida pelo positivismo, mas, pelo contrário, adotaria o ponto de vista apenas deste atores sem expôr este filtro. Critica ainda os estudos que, de uma perspectiva antropológica, ainda que se proponham a estudar o PCC, se orientam pelos ideais do Estado de Direito. Ao partir deste referencial de leitura, estes trabalhos diriam muito mais sobre os pesquisadores do que sobre o PCC, constituindo o que a autora brilhantemente caracterizou como uma "ciência social do (e sobre o) observador" (p.54).

Assim, os artigos desta seção indicam que, apesar de ainda serem poucos os estudos sobre as facções brasileiras, os autores que se dedicam a este objeto já têm desenvolvido discussões acerca de métodos e formas de investigação do mesmo, o que é um importante 
indicativo de comprometimento dos autores com o desenvolvimento de pesquisas qualificadas sobre o tema.

\section{CONCLUSÃO}

O número ínfimo de obras científicas que tratem do tema de maneira central ou minimamente razoável demonstra a maneira insuficiente como o objeto vem sendo abordado em termos de pesquisa científica. A grande maioria das publicações é recente, de 2006 em diante, o que pode ser um desdobramento do processo de nacionalização das facções do sudeste e de suas consequências na transformação da criminalidade urbana em outros pontos do território nacional. Como apontado pelos estudos aqui analisados, a presença das facções provoca diversos efeitos no território, tais como a substituição de gangues por grupos faccionais, expulsão de moradores de suas casas, imposição de regras para convivência dentro e fora do ambiente carcerário. Tais regras frequentemente são incorporadas, inclusive, pelo planejamento institucional, dinâmica que se verifica de maneira análoga no interior do sistema socioeducativo. A difusão de grupos faccionais de maneira mais ampla pelo território pode ser o principal fator de mudança no interesse dos pesquisadores acerca do objeto das facções a partir de 2006.

A maioria dos estudos abordou as facções do estado do Rio, de São Paulo e do Ceará. Quanto aos subtemas abordados, a maioria discutiu a relação dos grupos faccionais com o território no qual se inserem ou os eventos relacionados às facções nas prisões, o que é um subtema de fundamental relevância para compreender a história e as ideologias que envolvem o surgimento das facções brasileiras.

\section{CONSIDERAÇÕES FINAIS}

Abordar o objeto das facções brasileiras é tratar de um fenômeno cujos efeitos são flagrantes, numerosos e complexos. É urgente a ampliação de estudos que se debrucem sobre o tema, para melhor compreendê-lo e a partir disto, promover transformações na opinião social e científica que permitam enxergar sua existência como grupos de resistência, além de promover rearranjos quanto àqueles dos seus efeitos que sejam nocivos para a vida social. A urgência está, sobretudo, em minimizar tais efeitos sem cair em 
discursos preconceituosos, rasos ou que se utilizem práticas violentas e nocivas das facções para justificar políticas de criminalização, encarceramento em massa ou genocídio de determinadas populações. Como este tipo de estratégia criminalizadora por parte do Estado não é recente nem pontual, não parece promissor aguardar mudanças nesta lógica, mas sim implicar-se, assumir protagonismo e contribuir para o urgente movimento de mudança com o qual a ciência e a pesquisa nacional têm muito a contribuir.

O presente trabalho, ao mapear as publicações sobre o tema, pretende abrir caminhos para tal, servindo de referência e auxílio aos pesquisadores interessados a identificarem os numerosos determinantes e fatores relevantes que ainda precisam ser investigados acerca das facções.

\section{REFERÊNCIAS}

AMORIM, Carlos. Comando Vermelho: a história secreta do crime organizado. Rio de Janeiro: Best Seller, 2oIr.

AMORIM, Carlos. CV-PCC: a irmandade do crime. Rio de Janeiro: Editora Record, 2006.

AQUINO, Jania; HIRATA, Daniel Veloso. Inserções etnográficas ao universo do crime: algumas considerações sobre pesquisas realizadas no Brasil entre 2000 e 2017. Revista Brasileira de Informação Bibliográfica em Ciências Sociais, v. 84, p. 107-I47, 9 out. 2018. DOI I0.17666/bib8404/2018. Disponível em: http://www.anpocs.com/index.php/bib$\mathrm{pt} / \mathrm{bib}-84 /$ IIIoz-insercoes-etnograficas-ao-universo-do-crime-algumas-consideracoes-sobrepesquisas-realizadas-no-brasil-entre-2000-e-2017/file. Acesso em: 3 ago. 2021.

BENICIO, Luis Fernando de Souza; BARROS, João Paulo Pereira; RODRIGUES, Jéssica da Silva; SILVA, Dagualberto; LEONARDO, Camila dos Santos; COSTA, Aldemar. Necropolítica e Pesquisa-Intervenção sobre Homicídios de Adolescentes e Jovens em Fortaleza, CE. Psicologia: Ciência e Profissão, v. 38, n. spe2, p. 192-207, 2018. DOI 10.1590/1982-3703000212908. Disponível em: http://www.scielo.br/scielo.php?script=sci_arttext\&pid=SI4I4$98932018000600192 \& t \operatorname{lng}=p t$. Acesso em: 3 ago. 202I.

BILL, MV.; ATHAYDE, Celso. Falcão: meninos do tráfico. Rio de Janeiro, RJ: Objetiva : CUFA, Central Única das Favelas, 2006.

BIONDI, Karina. Proibido roubar na quebrada: território, hierarquia e lei no PCC. Rio de Janeiro, RH : São Paulo, SP: Gramma ; Editora Terceiro Nome, 2or8(Antropologia hoje). 
BRASIL. Lei № 12.850 /2013. Define organização criminosa e dispõe sobre a investigação criminal, os meios de obtenção da prova, infrações penais correlatas e o procedimento criminal; altera o Decreto-Lei no 2.848, de 7 de dezembro de 1940 (Código Penal); revoga a Lei no 9.034, de 3 de maio de 1995; e dá outras providências.

CUERVO CEBALLOS, Geraldine. El crimen organizado transnacional como una amenaza híbrida para la Triple Frontera (Argentina, Paraguay y Brasil). Revista Científica General José María Córdova, v. 16, n. 23, p. 43-61, 30 jun. 2018. DOI 10.21830/19006586.304. Disponível

em: https://www.revistacientificaesmic.com/index.php/esmic/article/view/304. Acesso em: 3 ago. 202I.

FELTRAN, Gabriel de Santis. Crime e castigo na cidade: os repertórios da justiça e a questão do homicídio nas periferias de São Paulo. Caderno CRH, v. 23, n. 58, p. 59-73, abr. 2010. DOI 10.1590/Soro3-4979201000oroooo5. Disponível em: http://www.scielo.br/scielo.php?script=sci_arttext\&pid=Soro3$49792010000100005 \& \operatorname{lng}=$ pt\&tlng=pt. Acesso em: 3 ago. 2021.

FELTRAN, Gabriel de Santis. Governo que produz crime, crime que produz governo: o dispositivo de gestão do homicídio em São Paulo (1992-2011). v. 6, n. 2, p. 24, 2012.

FELTRAN, Gabriel de Santis. Irmãos: uma história do PCC. São Paulo, SP: Companhia 145 Das Letras, 2018.

GODOI, Rafael. Experiência da pena e gestão de populações nas penitenciárias de São Paulo, Brasil. Etnografica, n. vol. 2I (I), p. 27-48, I fev. 2017. DOI I0.400o/etnografica.4805. Disponível em: http://journals.openedition.org/etnografica/4805. Acesso em: 3 ago. 202I.

HERNÁNDEZ, Jimena de Garay.; UZIEL, Anna. Paula; FERREIRA DO NASCIMENTO, M. A.; ALVES PINHO, G. S. Sentidos e práticas de paternidade: vozes de homens jovens em privação de liberdade. Polis (Santiago), v. 17, n. 50, p. 69-90, ago. 2018. DOI 10.4067/So718-65682018000200069. Disponível em: http://www.scielo.cl/scielo.php?script=sci_arttext\&pid=So718-

65682018000200069\&lng=en\&nrm=iso\&tlng=en. Acesso em: 3 ago. 2021.

HIRATA, Daniel Veloso; GRILLO, Carolina Christoph. Sintonia e amizade entre patrões e donos de morro: perspectivas comparativas entre o comércio varejista de drogas em São Paulo e no Rio de Janeiro. Tempo Social, v. 29, n. 2, p. 75, 8 ago. 2017. DOI 10.11606/oro32070.ts.2017.125494. Disponível em: https://www.revistas.usp.br/ts/article/view/125494. Acesso em: 3 ago. 202I.

LESSA, Bruno de Souza; SOUZA, Ana Clara Aparecida Alves. "THERE IS NO WHITE FLAG AND NO CHANCE OF GOING TO JAIL!" THE VIOLENT RELATIONS BETWEEN POLICE AND CRIMINALS IN FACÇÃO CENTRAL'S RAP SONGS. Linguagem em (Dis)curso, v. 20, n. I, p. 197-210, abr. 2020. DOI 
10.1590/1982-4017-200112-6819.

Disponível

em:

http://www.scielo.br/scielo.php?script=sci_arttext\&pid=SI5I8-

76322020000100197\&tlng=en. Acesso em: 3 ago. 202I.

LESSING, Benjamin. As facções cariocas em perspectiva comparativa. Novos Estudos CEBRAP, n. 8o, p. 43-62, mar. 2008. DOI 10.1590/Soroi-3300200800o100004. Disponível em: http://www.scielo.br/scielo.php?script=sci_arttext\&pid=SoroI$33002008000100004 \& \operatorname{lng}=$ pt $\&$ tlng=pt. Acesso em: 3 ago. 2021.

LIMA, William da Silva. 400 x I: uma história do comando vermelho. Rio de Janeiro: ANF produções, 2016.

MANSO, Bruno Paes; DIAS, Camila Caldeira Nunes. A guerra: a ascensão do PCC e o mundo do crime no Brasil. São Paulo, SP: Todavia, 2018.

MATTOS, Carla dos Santos. UMA ETNOGRAFIA DA EXPANSÃO DO MUNDO DO CRIME NO RIO DE JANEIRO. Revista Brasileira de Ciências Sociais, v. 3I, n. 9I, p. oI, 4 jul. 2016. DOI I0.17666/319110/2016. Disponível em: http://www.scielo.br/pdf/rbcsoc/v3ingI/oioz-6909-rbcsoc-31911020I6.pdf. Acesso em: 3 ago. 202I.

MISSE, Michel. Cinco Teses Equivocadas sobre a Criminalidade Urbana no Brasil*., p. I9, I995. .

MISSE, Michel. Crime organizado e crime comum no Rio de Janeiro: diferenças e afinidades. Revista de Sociologia e Política, v. 19, n. 40, p. 13-25, out. 2011. DOI 10.1590/Soro4-44782011000300003. Disponível

em:

http://www.scielo.br/scielo.php?script=sci_arttext\&pid=Soro4-

$44782011000300003 \& \operatorname{lng}=$ pt\&tlng=pt. Acesso em: 3 ago. 2021.

NASCIMENTO, Francisco Elionardo; MARQUES, Roberto; OSTERNE, Maria do Socorro Ferreira. Relações e relacionamentos de pessoas LGBT em prisão masculina: Entre normas e limites do dentro e fora da prisão. Dilemas - Revista de Estudos de Conflito e Controle Social, v. 13, n. 2, p. 297-316, is maio 2020. DOI io.17648/dilemas.vi3n2.20088. Disponível em: https://revistas.ufrj.br/index.php/dilemas/article/view/20088. Acesso em: 3 ago. 2021.

RAPOSO, Otávio. "This is Iraq. People are afraid." Resistance and mobilization in the Maré favelas (Rio de Janeiro). Vibrant: Virtual Brazilian Anthropology, v. II, n. I, p. II-49, jun. 2014. DOI I0.1590/Si809-4341201400oroooor. Disponível em: http://www.scielo.br/scielo.php?script=sci_arttext\&pid=Sr8o9434120140001000oI\&lng=en\&tlng=en. Acesso em: 3 ago. 2021.

REIS NETTO, Roberto; CHAGAS, Clay Anderson Nunes. Associação interna como forma de integração dos presídios às redes externas do tráfico: a percepção dos agentes 
territoriais da segurança pública no estado do Pará. Revista Direito GV, v. 15, n. 2, p. e1923, 2019. DOI I0.1590/2317-6172201923. Disponível em: http://www.scielo.br/scielo.php?script=sci_arttext\&pid=SI8o824322019000200210\&tlng=pt. Acesso em: 3 ago. 2021.

RODRIGUES, Fernando de Jesus. "CORRO COM O PCC”, "CORRO COM O CV", "SOU DO CRIME" Facções, sistema socioeducativo e os governos do ilícito em Alagoas. Revista Brasileira de Ciências Sociais, v. 35, n. IO2, p. e3510216, 2020. DOI 10.1590/3510216/2020. Disponível em: http://www.scielo.br/scielo.php?script=sci_arttext\&pid=Soro2$69092020000100515 \&$ tlng=pt. Acesso em: 3 ago. 2021

RUI, Taniele. Por entre territórios visíveis e territórios invisibilizados: mercados ilícitos e cracolândias de São Paulo e Rio de Janeiro. Novos Estudos - CEBRAP, v. 38, n. 3, p. 573588, dez. 2019. DOI 10.25091/Soro13300201900030004. Disponível em: http://novosestudos.uol.com.br/produto/II5/\#5eoaba87ca68d. Acesso em: 3 ago. 2021.

PAIVA, Luis Fábio. "AQUI NÃO TEM GANGUE, TEM FACÇÃO”: AS TRANSFORMAÇÕES SOCIAIS DO CRIME EM FORTALEZA. Caderno CRH, v. 32, n. 85, p. 165, 7 jun. 2019. DOI 10.977I/ccrh.v32i85.26375. Disponível em: https://portalseer.ufba.br/index.php/crh/article/view/26375. Acesso em: 3 ago. 202I.

SAMPÓ, Carolina; QUIRÓS, Ludmila; PETRINO, Jessica. La Guerra Urbana en Río de Janeiro: de las Unidades de Policía Pacificadora a la militarización (2008-2018). Revista Relaciones Internacionales, Estrategia y Seguridad, v. I4, n. I, p. 151-166, 28 fev. 2020. DOI I0.18359/ries.3727. Disponível em: https://revistas.unimilitar.edu.co/index.php/ries/article/view/3727. Acesso em: 3 ago. 2021.

SCHABBACH, Leticia; PASSOS, Iara Cunha. A produção da ordem no Presídio Central de Porto Alegre pela Polícia Militar. Revista Direito GV, v. I6, n. 2, p. e1963, 2020. DOI I0.1590/2317-6172201963. Disponível em: http://www.scielo.br/scielo.php?script=sci_arttext\&pid=SI8o8$24322020000200205 \&$ tlng=pt. Acesso em: 3 ago. 2021.

SILVA FILHO, Francisco Claudio Oliveira; MARIANO, Cynara Monteiro. Fronteiras invisíveis e deslocamentos forçados: impactos da "guerra" de facções na periferia de Fortaleza (Ceará, Brasil). Revista Direito e Práxis, v. II, n. 3, p. 1548-1570, set. 2020. DOI 10.1590/2179-8966/2019/43288. Disponível em: http://www.scielo.br/scielo.php?script=sci_arttext\&pid=S2179$89662020000301548 \&$ tlng=pt. Acesso em: 3 ago. 2021.

VARELLA, Drauzio. Prisioneiras. São Paulo, SP: Companhia Das Letras, 2017. 
ZALUAR, Alba; BARCELLOS, Christovam. Mortes prematuras e conflito armado pelo domínio das favelas no Rio de Janeiro. Revista Brasileira de Ciências Sociais, v. 28, n. 8I, p. 17-31, fev. 2013. DOI 10.1590/Soro2-69092013000100002. Disponível em: http://www.scielo.br/scielo.php?script=sci_arttext\&pid=Soroz-

69092013000100002\&lng=pt\&nrm=iso\&tlng=en. Acesso em: 3 ago. 2021. 